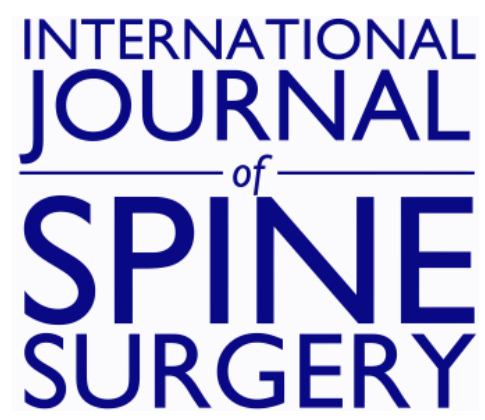

\title{
Physician-Specific Variability in Spine Fusion Patients
}

ANTHONY ZOU, JOSEPH BOSCO, THEMISTOCLES PROTOPSALTIS and JAMES SLOVER

Int J Spine Surg 2018, 12 (1) 37-42

doi: https://doi.org/10.14444/5007

http://ijssurgery.com/content/12/1/37

This information is current as of April 26, 2023.

Email Alerts Receive free email-alerts when new articles cite this article. Sign up at: http://ijssurgery.com/alerts 


\title{
Physician-Specific Variability in Spine Fusion Patients
}

\author{
ANTHONY ZOU, BA, ${ }^{1}$ JOSEPH BOSCO, MD ${ }^{2}$ THEMISTOCLES PROTOPSALTIS, MD ${ }^{2}$ JAMES SLOVER, \\ $\mathrm{MD}, \mathrm{MS}^{2}$ \\ ${ }^{I}$ New York University School of Medicine, New York, New York, ${ }^{2}$ Department of Orthopedic Surgery, New York University Langone Orthopedic Hospital, New \\ York, New York
}

\begin{abstract}
Background: It is often assumed that each surgeon's patient population is similar to that of his or her peers. Differences in patient characteristics naturally may lead to diverse outcomes. To date, the variability of individual surgeons' patient populations has not been adequately characterized. The purpose of this study is to describe the variation in physician-specific patient characteristics among surgeons performing spine fusion surgery at a large, urban academic medical center.

Methods: We analyzed administrative data from a single institution for spine fusion surgery from 2009 to 2013. There were 6585 primary and 362 revision cases of spine fusion performed within this time period. Variability between surgeons and their respective patient populations was compared using descriptive statistics.

Results: The mean annual percentage of primary fusion patients with diabetes mellitus ranged from 0 to $16.17 \%$ (mean $\pm \mathrm{SD}, 7.79 \% \pm 3.96 \%$ ) but constituted anywhere from 0 to $41.58 \%$ (mean $\pm \mathrm{SD}, 8.15 \% \pm 12.09 \%$ ) of revision fusions. The mean annual percentage of primary fusion patients who were obese ranged from 0 to $9 \%$ (mean $\pm \mathrm{SD}$, $2.95 \% \pm 2.7 \%$ ), and 0 to $25 \%$ in revision cases (mean $\pm \mathrm{SD}, 3.43 \% \pm 6.43 \%$ ). The annual mean percentage of patients with American Society of Anesthesiologists (ASA) scores greater than 3 ranged from 8.8\% to 44.43\% (mean \pm SD, $20.42 \% \pm 8.85 \%$ ) in primary fusions and 0 to $100 \%$ (mean $\pm \mathrm{SD}, 32.79 \% \pm 23.47 \%$ ) in revision fusions.

Conclusion: There was a large amount of variability among surgeons' patient populations when looking at characteristics such as obesity, diabetes, and ASA scores $>3$. These factors have been shown to impact patient outcomes. The variability in the patient populations of individual surgeons' practices even within the same medical center must be taken into account when evaluating physician specific outcomes and quality of care.
\end{abstract}

Other \& Special Categories

Keywords: patient variability, risk adjustment, spine fusion, physician outcomes

\section{INTRODUCTION}

The incidence of spine fusion surgery in the United States is rapidly increasing and has more than doubled from 1998, , $^{1,}$ outstripping growth in other common orthopaedic procedures, such as hip and knee arthroplasty. Spine fusion surgery also incurs increasingly high financial $\operatorname{costs}^{2,3}$ and is associated with complications such as infection, pseudarthrosis, and adjacent-level disease, which significantly impact patient outcomes and cost. ${ }^{4-7}$ In particular, risk factors for infection include diabetes mellitus, obesity, and worse comorbidity burden. ${ }^{8,9}$ The presence of these risk factors for infection may vary across different surgeons' practices, and little research has been done to explore these potential differences. It is important to understand the risk factors for infection that impact patient outcomes, both for appropriate patient counseling and for fair comparison of quality performance among different surgeons. The prevalence and importance of physician performance evaluation have increased in recent years, and perhaps most notably, the Medicare Access and CHIP Reauthorization Act will soon tether value to provider reimbursement for the Medicare population. ${ }^{10}$ The purpose of this study was to compare the practice compositions of different surgeons from a single, large academic medical center to determine whether there is significant variation in patient characteristics for individual surgeon practices.

\section{MATERIALS AND METHODS}

We retrospectively analyzed cross-sectional data from an institutional database. Our study consisted of 6585 cases of primary spine fusion and 362 cases of revision spine fusion performed by 22 and 24 surgeons, respectively, in our single-specialty institution during a 5-year time frame (2009-2013). The 
Table 1. Variable factors in health care delivery.

\begin{tabular}{cc}
\hline Patient & Age, commercial insurance, Medicaid insurance, \\
& Medicare insurance, diabetes mellitus, body mass \\
index $>30$, tobacco users, same-day admission, \\
American Society of Anesthesiologists score \\
Perioperative & Operative time, packed red blood cells used, $>9$ \\
& spine levels fused, lower levels fused \\
\hline
\end{tabular}

factors that constituted variability were divided into patient and perioperative considerations (Table 1).

Variability among surgeons and their respective patient populations was illustrated using descriptive statistics (mean, range, standard deviation, maximum, minimum).

\section{RESULTS}

We analyzed a total of 6585 cases of primary spine fusion and 362 cases of revision spine fusion performed by 22 and 24 surgeons, respectively, in our single-specialty institution during a 5-year time frame (2009-2013). The mean annual ages across each surgeon's patient population for primary and revision fusion ranged from 14.01 to 57 years (mean $\pm \mathrm{SD}, 44.84 \pm 10.72$ years) and 14 to 69 years $(55.36 \pm 10.8$ years), respectively. The mean annual percentage of primary fusion patients with commercial insurance $(29.32 \% \pm 18.9 \%)$ was an overwhelmingly larger percentage than those with Medicaid $(0.76 \% \pm 1.37 \%)$ or Medicare $(7.41 \%$ $\pm 7.94 \%$ ). Revision fusion data showed a large proportion of commercial insurance $(34.83 \% \pm$ $29.23 \%)$ and Medicare patients (19.75\% \pm $25.33 \%)$, and no Medicaid patients $(0 \pm 0)$. The mean annual percentage of primary fusion patients with diabetes mellitus ranged from 0 to $16.17 \%$ $(7.79 \% \pm 3.96 \%)$, and patients with diabetes constituted anywhere from 0 to $41.58 \%(8.15 \% \pm$ $12.09 \%$ ) of revision fusions. The mean annual percentage of primary fusion patients who were obese ranged from 0 to $9 \%(2.95 \% \pm 2.7 \%)$, and obesity ranged from 0 to $25 \%$ in revision cases $(3.43 \% \pm 6.43 \%)$, while tobacco users comprised 0 to $19.95 \%$ of surgeons' average annual patient populations $(10.17 \% \pm 6.1 \%)$ in primary fusions and 0 to $50 \%$ in revision fusions $(12.79 \% \pm$ $13.63 \%$ ). Same-day admissions constituted almost all primary and revision spine fusion surgeries and ranged from $88 \%$ to $100 \%(91.9 \% \pm 3.57 \%)$ and $60 \%$ to $100 \%(90.16 \% \pm 11.51 \%)$ of surgeons' mean annual percentages, respectively. The annual mean percentage of patients with American Society of Anesthesiologists (ASA) scores $>3$ ranged from $8.8 \%$ to $44.43 \%(20.42 \% \pm 8.85 \%)$ in primary fusions and 0 to $100 \%(32.79 \% \pm 23.47 \%)$ in revision fusions.

\section{Perioperative Variability}

Perioperative variables were analyzed to characterize differences in surgeon practices in the operating room. The mean annual operating time ranged from 145.66 to 495.91 minutes (255.94 \pm 105.03 minutes) in primary fusions and 231 to 1204 minutes (469.79 \pm 251.88 minutes) in revision cases. The mean annual percentage of primary surgeries in which packed red blood cells (pRBCs) were used ranged from 0 to $27.54 \%(8.92 \% \pm 8.25 \%)$, whereas the average units of pRBCs used in such instances ranged from 0 to 2.89 (1.53 \pm 0.85 units). Revision surgeries required more frequent use and greater quantities of blood transfusions, because pRBC use ranged from 0 to $100 \%(29.63 \% \pm$ $29.18 \%$ ), whereas the average units of pRBCs used in such instances ranged from 0 to $8(1.98 \pm 2.07$ units). The mean annual percentage of greater than 9 spine levels fused ranged from 0 to $57.18 \%$ $(10.09 \% \pm 15.96 \%)$ in primary cases and 0 to $100 \%$ $(16.09 \% \pm 29.28 \%)$ in revision cases. The percentage of patients who required lower-level spine fusions ranged from $11.91 \%$ to $64 \%(36.7 \% \pm$ $12.1 \%)$ in primary cases and $33 \%$ to $100 \%(82.56 \%$ $\pm 17.77 \%$ ) in revision cases.

\section{DISCUSSION}

Performance has been evaluated at the institutional level, and public reporting of quality data has become increasingly prevalent. However, there has been little effort to characterize any potential existing variability in patient populations at the physician level. From a provider perspective, it has been shown that quality increases after performance is evaluated and disseminated publicly or only among physicians. ${ }^{11-15}$ However, there remain concerns on the fairness of public reporting of individual physicians' performance, as the recent ProPublica Surgeon's Report Card has reinforced. ${ }^{16}$ Obstacles that have prevented the fair and accurate measurement of physician performance include poor measure reliability and limited or incomplete data for adequate risk adjustment at the physician level. ${ }^{1,17}$ This study demonstrates that variation in patients' infection risk factors for different surgeons 
Table 2. Primary spine fusion data (per year).

\begin{tabular}{|c|c|c|c|c|c|}
\hline Variability Type and Factor & Mean & Minimum & Maximum & Range & Standard Deviation \\
\hline \multicolumn{6}{|l|}{ Patients } \\
\hline Mean age, y & 55.36 & 14 & 69 & 55 & 10.8 \\
\hline Commercial, \% & 34.83 & 0 & 100 & 100 & 29.23 \\
\hline Medicaid, $\%$ & 0 & 0 & 0 & 0 & 0 \\
\hline Medicare, \% & 19.75 & 0 & 100 & 100 & 25.33 \\
\hline Diabetes, \% & 8.15 & 0 & 41.58 & 41.58 & 12.09 \\
\hline Body mass index $>30, \%$ & 3.43 & 0 & 25 & 25 & 6.43 \\
\hline Tobacco users, $\%$ & 12.79 & 0 & 50 & 50 & 13.63 \\
\hline Same-day admissions, $\%$ & 90.16 & 60 & 100 & 40 & 11.51 \\
\hline ASA scores $>3, \%$ & 32.79 & 0 & 100 & 100 & 23.47 \\
\hline \multicolumn{6}{|l|}{ Perioperative } \\
\hline Mean operation time, min & 469.79 & 231 & 1204 & 973 & 251.88 \\
\hline Mean operation time, min & 470.44 & 188.73 & 1204 & 1015.27 & 264.24 \\
\hline pRBCs, $\%$ & 29.63 & 0 & 100 & 100 & 29.18 \\
\hline Mean units of $\mathrm{pRBCs}$ & 1.98 & 0 & 8 & 8 & 2.07 \\
\hline$>9$ spine levels, $\%$ & 16.09 & 0 & 100 & 100 & 29.28 \\
\hline Lower levels, \% & 82.56 & 33 & 100 & 67 & 17.77 \\
\hline
\end{tabular}

Abbreviations: ASA, American Society of Anesthesiologists; pRBCs, packed red blood cells.

that may impact quality measurement and reporting exist. The characterization of intersurgeon variability in patient risk factors associated with postoperative complications is an important step in evaluating future metrics of physician-level quality assessment. ${ }^{11-15,18-21}$ The demonstration of variability and efforts to reduce this variability where appropriate may be one strategy for improving patient outcomes.

There is great variation in the complexity of spine surgery and in infection risk factors for individual physician practices at a single urban academic medical center. In our single-institution data set, we demonstrated significant variability among physician patient populations.

The incidence of diabetic patients among surgeons varied from 0 to $16.17 \%$ in the primary fusion cohort (Figure 1 and Table 2) and from 0 to $25 \%$ in the revision fusion cohort (Figure 2 and Table 3). In 4 of the 22 surgeons performing primary fusions, diabetic patients constituted only $4 \%$ or less of their patient populations. Diabetes is a strong risk factor for developing postsurgical infections and delayed healing, which could partially contribute to the apparent reluctance of many surgeons in our cohort to perform spine fusions. ${ }^{22-25}$ However, even in spite of the 6- to 8-fold increased risk of developing surgical site infections reported in the literature, diabetic patients constituted more than $10 \%$ of 5 surgeons' patient populations in the primary fusion cohort.

Obesity in surgeons' populations seemed to be clustered around a bimodal distribution in the primary fusion group, with 5 surgeons' patient populations comprising $6 \%$ to $9 \%$ obese patients and the other 17 having less than $4 \%$ (Figure 1 and

Table 3. Revision spine fusion data (per year)

\begin{tabular}{|c|c|c|c|c|c|}
\hline Variability Type and Factor & Mean & Minimum & Maximum & Range & Standard Deviation \\
\hline \multicolumn{6}{|l|}{ Patient } \\
\hline Mean age, y & 44.84 & 14.01 & 57 & 42.99 & 10.72 \\
\hline Median age, $y$ & 45.2 & 14.05 & 65.38 & 51.33 & 13.71 \\
\hline Commercial, $\%$ & 29.32 & 0 & 77.51 & 77.51 & 18.9 \\
\hline Medicaid, \% & 0.76 & 0 & 5.51 & 5.51 & 1.37 \\
\hline Medicare, \% & 7.41 & 0 & 29.78 & 29.78 & 7.94 \\
\hline Diabetes, \% & 7.79 & 0 & 16.17 & 16.17 & 3.96 \\
\hline Body mass index $>30, \%$ & 2.95 & 0 & 9 & 9 & 2.7 \\
\hline Tobacco users, $\%$ & 10.17 & 0 & 19.95 & 19.95 & 6.1 \\
\hline Same-day admissions, $\%$ & 91.9 & 88 & 100 & 12 & 3.57 \\
\hline ASA scores $>3, \%$ & 20.42 & 8.8 & 44.43 & 35.63 & 8.85 \\
\hline \multicolumn{6}{|l|}{ Perioperative } \\
\hline Mean operation time, min & 255.94 & 145.66 & 495.91 & 350.25 & 105.03 \\
\hline Median operation time, min & 206.8 & 100.09 & 502.09 & 402 & 108.42 \\
\hline $\mathrm{pRBCs}, \%$ & 8.92 & 0 & 27.54 & 27.54 & 8.25 \\
\hline Mean units of $\mathrm{pRBCs}$ & 1.53 & 0 & 2.89 & 2.89 & 0.85 \\
\hline$>9$ spine levels, $\%$ & 10.09 & 0 & 57.18 & 57.18 & 15.96 \\
\hline Lower levels, \% & 36.7 & 11.91 & 64 & 52.09 & 12.1 \\
\hline
\end{tabular}

Abbreviations: ASA, American Society of Anesthesiologists; pRBCs, packed red blood cells. 


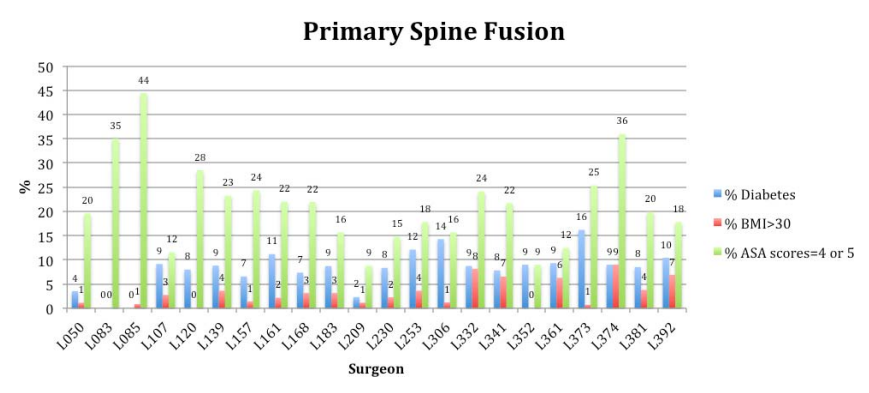

Figure 1. Surgeon case-mix (primary spine fusion). Abbreviations: BMI, body mass index; ASA, American Society of Anesthesiologists.

Table 2). Obesity was even less commonly found in revisions, because 13 of the 23 surgeons did not perform surgery on obese patients in a revision setting (Figure 2 and Table 3). However, obese patients constituted $20 \%$ or more of 2 of the surgeons' populations in the revision cohort. Patients who reported tobacco use ranged from 0 to $19.95 \%$ in the primary fusion cohort (Figure 1 and Table 2) and from 0 to $50 \%$ in the revision fusion cohort (Figure 2 and Table 3). A total of 5 of the 22 surgeons performing primary fusions performed less than $5 \%$ of their procedures on tobacco users, whereas 8 surgeons operated on tobacco users more than $15 \%$ of the time. The revision cohort showed a greater spread, because 9 surgeons did not perform spine fusions on tobacco users at all, whereas tobacco use was prevalent in more than $15 \%$ of procedures in 10 of the surgeons' populations. Obesity and tobacco use have been associated with an increased risk of developing surgical site infections, higher hospital costs, and other complications, making them clinically relevant risk factors that must be evaluated in the context of performance assessment. ${ }^{24-27}$

A large variation, ranging from $7 \%$ to $44 \%$, of patient populations with ASA scores $>3$ was seen among the 22 surgeons performing primary fusions (Figure 1 and Table 2). Revision fusion patient populations evidenced a higher proportion of ASA scores $>3$ than primary fusion populations (Figure 2 and Table 3), possibly reflecting the inherently greater baseline risk in this patient population. Higher ASA scores have been correlated with increased cost and likelihood of developing major complications after spine fusion. ${ }^{25,28}$

The characterization of intersurgeon variability in patient risk factors associated with postoperative complications is an important step in minimizing the likelihood that a physician will be held accountable for aspects of care beyond his or her

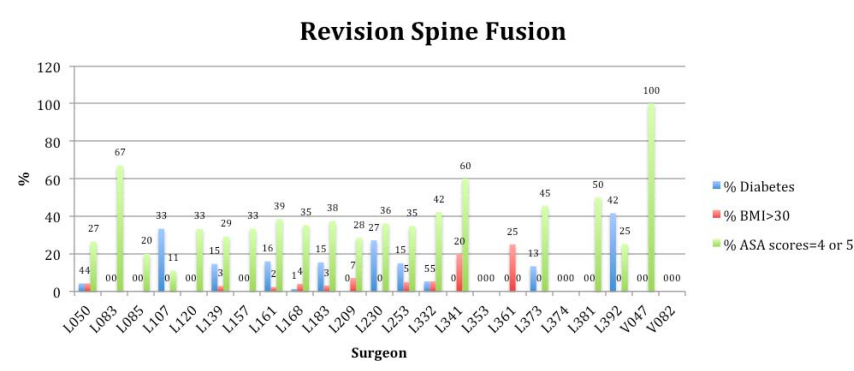

Figure 2. Surgeon case-mix (revision spine fusion). Abbreviations: BMI, body mass index; ASA, American Society of Anesthesiologists.

control in future metrics of physician-level quality assessment. Proper risk adjustment involves accounting for variation in patient characteristics, or case-mix bias, so that physicians who treat sicker patients do not appear to provide a lower quality of care compared with their peers. It is imperative that this variation be accounted for in order to more accurately represent a physician's performance. This is especially true for spine surgeons because there is great variability in spinal fusion procedures. This variability includes the number of levels fused and revision versus nonrevision surgery. Each of these types of fusions carries a different risk of complications. For example, adult spinal deformity surgery has especially proven to be associated with high complication rates and costly hospital stays and will be difficult to incorporate into a bundled payment program. ${ }^{29}$ In a single-center retrospective analysis of 448 consecutive adult spinal deformity surgeries from 2005 to 2011, McCarthy et al. $^{30}$ found an average cost of $\$ 103,143$ per patient during primary hospital stays. Additionally, many complications in spine surgery do not lead to clinically significant differences in outcome, as put forth by Smith et al, ${ }^{31}$ and it will be important to isolate variables that have clinically significant impacts on long-term outcomes.

The ramifications of appropriately characterizing the risk characteristics of patient populations are compelling. Surgeons who operate on the most severely ill patients may appear to provide poorerquality care compared with their colleagues who take on patients with an average risk profile. Such a misrepresentation misleads consumers, results in inappropriate payment allocation in quality-based payment programs, and misguides policy efforts towards quality improvement. ${ }^{32,33}$ Because we know that there are certain risk factors associated with an increase in surgical site infection rate and other negative outcomes, ${ }^{22,24}$ some surgeons who operate on patients outside an acceptable range of risk 
should be more judicious about on whom they perform fusions or focus more on optimizing the patient, when able.

In our study we were able to display the case-mix of each surgeon individually, data that have not been shown before in the literature. However, one limitation is that surgical outcomes were not investigated and further follow-up studies to further delineate the association between case-mix and outcomes are needed. Selection bias is also a significant limitation in our study, as our purpose was to emphasize the variability in case-mix among surgeons all operating in the same institution. Future studies should include a large set of surgeons across a multiplicity of hospitals from various locations and practice settings to minimize this effect.

\section{CONCLUSION}

Significant variation of individual spine practices and patient populations within a single institution appears to exist. These differences can potentially be used to help surgeons improve patient outcomes. Quality assessment and reporting programs should make efforts to stratify and separately analyze outcomes and complications in cases involving revision surgery and patients with comorbidities associated with higher complications. Further investigation to evaluate the etiology of the variation in patient populations of different surgeons within the same urban academic medical centers is needed.

\section{REFERENCES}

1. Romano P, Hussey P, Ritley D (eds.). Part II: introduction to measures of quality. Selecting Quality and Resource Use Measures: A Decision Guide for Community Quality Collaboratives. http://www.ahrq.gov/professionals/ quality-patient-safety/quality-resources/tools/perfmeasguide/ perfmeaspt2.html. Accessed November 16, 2015.

2. Rajaee SS, Bae HW, Kanim LE, Delamarter RB. Spinal fusion in the United States: analysis of trends from 1998 to 2008. Spine (Phila Pa 1976). 2012;37(1):67-76.

3. Kirkland KB, Briggs JP, Trivette SL, Wilkinson WE, Sexton DJ. The impact of surgical-site infections in the 1990s: attributable mortality, excess length of hospitalization, and extra costs. Infect Control Hosp Epidemiol. 1999;20(11):725730 .

4. Deyo RA, Mirza SK. The case for restraint in spinal surgery: does quality management have a role to play? Eur Spine J. 2009;18(suppl 3):331-337.

5. Turner JA, Ersek M, Herron L, et al. Patient outcomes after lumbar spinal fusions. JAMA. 1992;268(7):907-911.

6. Hilibrand AS, Robbins M. Adjacent segment degener- ation and adjacent segment disease: the consequences of spinal fusion? Spine J. 2004;4(6 suppl):190S-194S.

7. Shriver MF, Lewis DJ, Kshettry VR, Rosenbaum BP, Benzel EC, Mroz TE. Pseudoarthrosis rates in anterior cervical discectomy and fusion: a meta-analysis. Spine J. 2015;15(9):2016-2027.

8. Pull ter Gunne AF, Hosman AJ, Cohen DB, et al. A methodological systematic review on surgical site infections following spinal surgery, part 1: risk factors. Spine (Phila $\mathrm{Pa}$ 1976). 2012;37(24):2017-2033.

9. Koutsoumbelis S, Hughes AP, Girardi FP, et al. Risk factors for postoperative infection following posterior lumbar instrumented arthrodesis. J Bone Joint Surg Am. 2011;93(17):1627-1633.

10. Findlay S. Physician compare (updated). In: Health Affairs Policy Brief. December 11, 2015. https://www. healthaffairs.org/do/10.1377/hpb20151029.358498/full/. Accessed November 7, 2017

11. Cohen ME, Liu Y, Ko CY, Hall BL. Improved surgical outcomes for ACS NSQIP hospitals over time: evaluation of hospital cohorts with up to 8 years of participation. Ann Surg. 2016;263(2):267-273.

12. Kolstad JT. Information and quality when motivation is intrinsic: evidence from surgeon report cards. Am Econ Rev. 2013;103(7):2875-2910.

13. Smith MA, Wright A, Queram C, Lamb GC. Public reporting helped drive quality improvement in outpatient diabetes care among Wisconsin physician groups. Health Aff (Millwood). 2012;31(3):570-577.

14. Fung CH, Lim YW, Mattke S, Damberg C, Shekelle PG. Systematic review: the evidence that publishing patient care performance data improves quality of care. Ann Intern Med. 2008;148(2):111-123

15. Ketelaar NA, Faber MJ, Flottorp S, Rygh LH, Deane $\mathrm{KH}$, Eccles MP. Public release of performance data in changing the behaviour of healthcare consumers, professionals or organisations. Cochrane Database Syst Rev. 2011(11): CD004538.

16. Friedberg MW, Pronovost PJ, Shahian DM, et al. $A$ Methodological Critique of the ProPublica Surgeon Scorecard. Santa Monica, CA: RAND Corporation; 2015.

17. Greenfield S, Kaplan SH, Kahn R, Ninomiya J, Griffith JL. Profiling care provided by different groups of physicians: effects of patient case-mix (bias) and physician-level clustering on quality assessment results. Ann Intern Med. 2002;136(2):111-121.

18. Faber M, Bosch M, Wollersheim H, Leatherman S, Grol R. Public reporting in health care: how do consumers use quality-of-care information?: a systematic review. Med Care. 2009;47(1):1-8.

19. Lubalin JS, Harris-Kojetin LD. What do consumers want and need to know in making health care choices? Med Care Res Rev. 1999;56(suppl 1):67-102; discussion 103-112.

20. Riskin L, Campagna JA. Quality assessment by external bodies: intended and unintended impact on healthcare delivery. Curr Opin Anaesthesiol. 2009;22(2):237-241.

21. Jha AK. Health care providers should publish physician ratings. Harvard Business Review. October 23, 2015. https://hbr.org/2015/10/health-care-providers-should-publishphysician-ratings. Accessed March 26, 2018.

22. Fang A, Hu SS, Endres N, Bradford DS. Risk factors 
for infection after spinal surgery. Spine (Phila Pa 1976). 2005;30(12):1460-1465.

23. Schimmel JJ, Horsting PP, de Kleuver M, Wonders G, van Limbeek J. Risk factors for deep surgical site infections after spinal fusion. Eur Spine J. 2010;19(10):1711-1719.

24. Olsen MA, Nepple JJ, Riew KD, et al. Risk factors for surgical site infection following orthopaedic spinal operations. $J$ Bone Joint Surg Am. 2008;90(1):62-69.

25. Schoenfeld AJ, Carey PA, Cleveland AW 3rd, Bader JO, Bono CM. Patient factors, comorbidities, and surgical characteristics that increase mortality and complication risk after spinal arthrodesis: a prognostic study based on 5,887 patients. Spine J. 2013;13(10):1171-1179.

26. Buerba RA, Fu MC, Gruskay JA, Long WD 3rd, Grauer JN. Obese class III patients at significantly greater risk of multiple complications after lumbar surgery: an analysis of 10,387 patients in the ACS NSQIP database. Spine $J$. 2014;14(9):2008-2018.

27. Higgins DM, Mallory GW, Planchard R, et al. Understanding the impact of obesity on short-term outcomes and in-hospital costs after instrumented spinal fusion. Neurosurgery. 2016;78(1):127-132.

28. Whitmore RG, Stephen JH, Vernick C, et al. ASA grade and Charlson Comorbidity Index of spinal surgery patients: correlation with complications and societal costs. Spine J. 2014;14(1):31-38.

29. Smith JS, Shaffrey CI, Sansur CA, et al.; Scoliosis Research Society Morbidity and Mortality Committee. Rates of infection after spine surgery based on 108,419 procedures: a report from the Scoliosis Research Society Morbidity and Mortality Committee. Spine (Phila Pa 1976). 2011;36(7):556563.

30. McCarthy IM, Hostin RA, Ames CP, et al.; International Spine Study Group. Total hospital costs of surgical treatment for adult spinal deformity: an extended follow-up study. Spine J. 2014;14(10):2326-2333.

31. Smith JS, Klineberg E, Lafage V, et al.; International Spine Study Group. Prospective multicenter assessment of perioperative and minimum 2-year postoperative complication rates associated with adult spinal deformity surgery. J Neurosurg Spine. 2016;25(1):1-14.

32. Dranove D, Kessler D, McClellan M, Satterthwaite M. Is more information better?: the effects of "report cards" on health care providers. NBER Working Paper Series No. 8697. Cambridge, Mass: National Bureau of Economic Research; 2002. http://papers.nber.org/papers/W8697.

33. Jauhar S. Giving doctors grades. New York Times. July 22, 2015:A27.

Disclosures and COI: No authors have conflicts of interest associated with this study.

Corresponding Author: Anthony Zou, BA, 334 East 26th Street, Apartment 23A1, New York, NY 10010. Phone: 908-884-6517; Email: Anthony. zou@med.nyu.edu.

Published 30 March 2018

This manuscript is generously published free of charge by ISASS, the International Society for the Advancement of Spine Surgery. Copyright @ 2018 ISASS. To see more or order reprints or permissions, see http://ijssurgery.com. 